http://jmscr.igmpublication.org/home/

ISSN (e)-2347-176x ISSN (p) 2455-0450

crossref DOI: https://dx.doi.org/10.18535/jmscr/v7i8.66

Journal Of Medical Science And Clinical Research

\title{
To assess the need of palliative care in children with cerebral palsy using Paediatric Palliative Screening Scale (PaPaS Scale)
}

\author{
Authors \\ Dr Vishal Jamwal ${ }^{1}$, Dr Gaurav Sharma ${ }^{2^{*}}$, Dr Pancham Kumar ${ }^{3}$, Dr Garima Sharma ${ }^{4}$ \\ ${ }^{1}$ Deptt. of Paediatrics, Indra Gandhi Govt. Medical College, Shimla, H.P. \\ ${ }^{2}$ Deptt. of Paediatrics, Indra Gandhi Govt. Medical College, Shimla , H.P. \\ ${ }^{3}$ Assistant Professor, Deptt. of Paediatrics, IGMC, Shimla \\ ${ }^{4}$ Senior Resident IGMC shimla \\ *Corresponding Author \\ Dr Gaurav Sharma \\ IGMC Shimla 171001, India
}

\begin{abstract}
Palliative care aims to cloak the patient's symptoms and provide comfort even when treatments aimed at cure are no longer possible. It begins when illness or the life limiting condition is diagnosed, and continues regardless of whether or not a child receives treatment directed at the disease. A number of scales designed to improve recognition of the need for palliative care eg. Edmonton Symptom Assessment Scale (ESAS), Paediatric Palliative Screening Scale (PaPaS Scale) etc. Based on these palliative care need is assessed and further care is provided.

The aim of this study was to assess the need of palliative care in children with severe cerebral palsy.
\end{abstract}

\section{Introduction}

The World Health Organization (WHO) states that 'Palliative care for children represents a special, albeit closely related field to adult palliative care and is the active total care of the child's body, mind and spirit, and also involves giving support to the family. ${ }^{(1)}$ It begins when illness is diagnosed, and continues regardless of whether or not a child receives treatment directed at the disease. In 1997, the Association of Children's Palliative Care (ACT) and Royal College of Pediatrics Child and Health published the first system to categorise life limiting and threatening conditions in childhood. ${ }^{(2)}$ Amongst the groups of life limiting diseases in children, severe cerebral palsy exemplify the conditions with severe neurological disability that although not progressive leads to vulnerability to complications leading to premature death. Gastrostomy tubes and nutritional supplements have been paramount in enhancing the life expectancy of those with CP. Recent literature shows that as many as $90 \%$ of patients with $\mathrm{CP}$ can now be expected to live to adulthood. A number of scales designed to improve recognition of the need for palliative care (3)(4) Edmonton Symptom Assessment Scale (ESAS), Paediatric Palliative Screening Scale (PaPaS Scale) etc. 


\section{Methods}

The study was carried out in the department of pediatrics IGMC Shimla, Himachal Pradesh. Assessment of the palliative care needs for the patient were carried out in both inpatient and outpatient hospital setting. It was a prospective study. All patients who presented during the study period, between one to eighteen years of age with severe cerebral palsy were included. Neonates and Infants were not included in the study. Study tool encompassed a proforma based on oral questionnaire. Modified Paediatric Palliative Screening Scale and (Modified PaPaS Scale) was used to assess the need of palliative care in the study group based on the following domains. It includes

1)Estimated life expectancy

2) Expected outcome of current treatment directed at the disease and burden of this treatment

3)Performance status

3.1 Current performance status was in comparison with the child's own baseline when the child was disease free and upon restriction of play

3.2 Rate of decline of performance status over the last 4 weeks

4) Symptom and problem burden were judged on

4.1 Number of symptoms (e.g. pain, weight loss, fatigue, dyspnoea, nausea \& vomiting, depression, anxiety)

4.2 Symptom intensity As perceived by the parents

4.3 Psychological distress judged by Kessler Psychological Distress Scale (K10)

5) Preferences of patient, family and health professional

\section{Result}

The need of palliative care in the group were assessed based on the following score:

Score $<15$ Needs no palliative care

Score 15-25 prepare start of palliative care

Score $>25$ - Needs palliative care and the care to be started immediately

\section{Results}

Total number of children of severe $\mathrm{CP}$ enrolled during the study period were 60 . Out of which 26 were male and 34 were female. Amongst them 48 were in the age group of 1 to 5 years and 10 in the age group of 6-10 years and 2 were more than 10 years. Modified Paediatric Palliative Screening Scale (Modified PaPaS Scale) was used to assess the need of palliative care in the study group which encompassed a performa based oral questionnaire. The need for palliative care was assessed according to score in 5 different domains. The domain 1 (Estimated life expectancy) all children had a score of 2 which meant that all had life expectancy greater than 2 years. In domain 2 (Expected outcome of current treatment directed at the disease and burden of this treatment) $20 \mathrm{had}$ a score 0-2 and 40between 2-4. In domain 3 (performance status) 28 had score of 0-2 while 32 had a score of 2-5. In domain 4 (Symptom and problem burden) 7 had a score of $0-5,47$ had a score of 6-10 and 6 had a score of 11-15. In domain 5 (Preferences of patient, family and health professional) 12 children had score equal to or less than 6 while 48 children had a score between 7-12.

The total score was added for each child, out of which 53 children had a score of 15-24 which meant in these children prepare start of palliative care was needed, and 7 had a score greater than 25 which meant that palliative care to be started immediately. All the 7 children with severe cerebral palsy who had a score of greater than 25 were more than 5 years old. The 2 children with severe cerebral palsy whose age was more than 10 years had the maximum score. 
Table 1 Age wise distribution of children enrolled

AGE
\begin{tabular}{|ll|c|c|c|c|}
\hline & & Frequency & Percent & Valid Percent & $\begin{array}{c}\text { Cumulative } \\
\text { Percent }\end{array}$ \\
\hline Valid & 1-5 years & 10 & 16.6 & 16.6 & 16.6 \\
& 5-10 years & 48 & 80 & 80 & 96.6 \\
& 10-15 years & 2 & 3.3 & 3.3 & 100.0 \\
& Total & 60 & 100.0 & 100.0 & \\
\hline
\end{tabular}

Table 2 Distribution of children according to gender

Gender

\begin{tabular}{|cl|c|c|c|c|}
\hline & & Frequency & Percent & Valid Percent & $\begin{array}{c}\text { Cumulative } \\
\text { Percent }\end{array}$ \\
\hline Valid & Male & 26 & 43 & 43 & 43 \\
& Female & 34 & 57 & 57 & 100.0 \\
& Total & 60 & 100.0 & 100.0 & \\
\hline
\end{tabular}
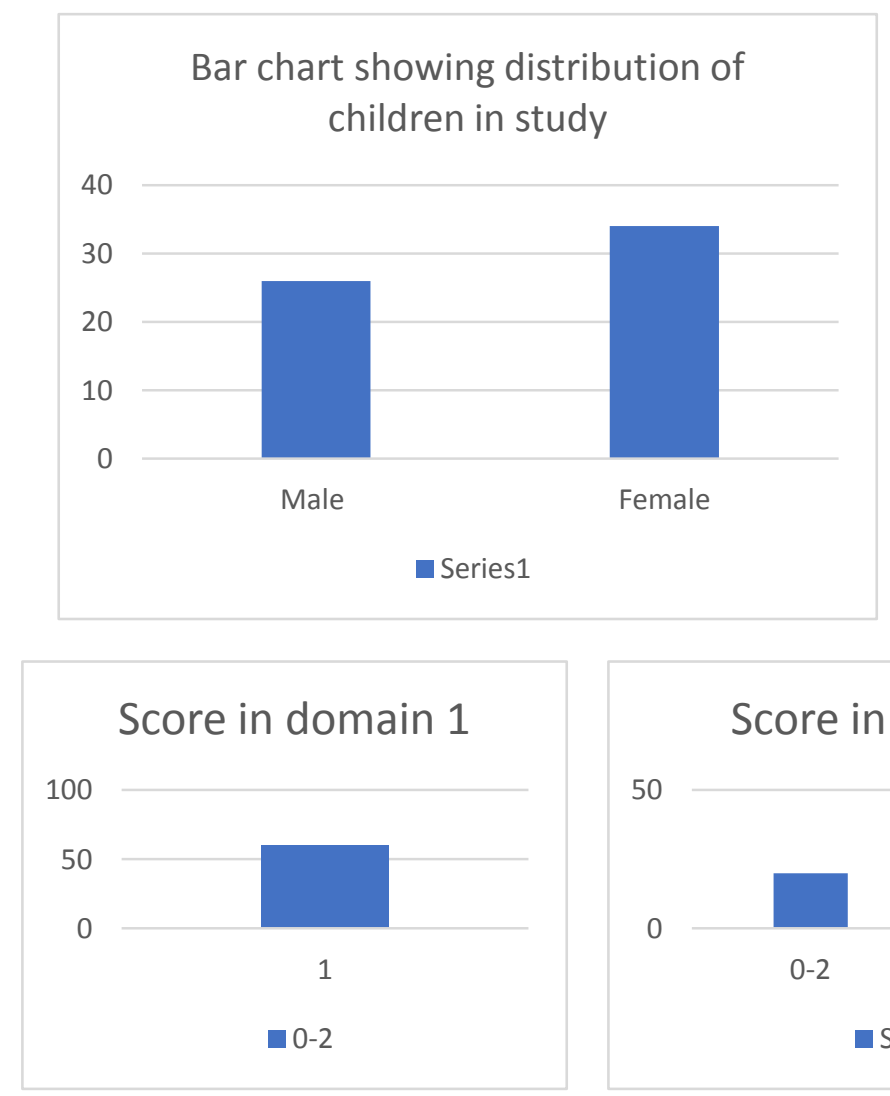

Score in domain 4 50

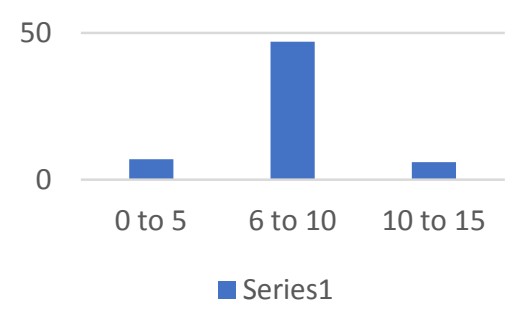

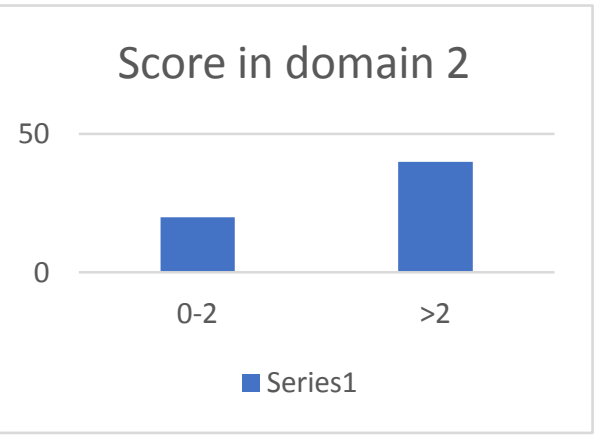

Score in domain 5 100

50

0

0 to 6

- Series1
Percentage of male (43\%) and female $(57 \%$ in study

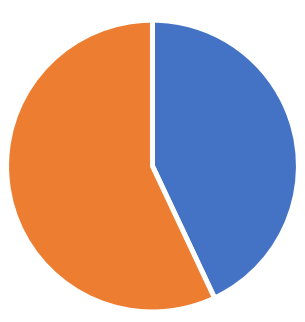

- Male - Female 


\section{Discussion}

Around $18 \%$ of children with cerebral palsy die in childhood. Acceptance criteria for children's hospices usually require the child to be likely to be life limited by the age of 25 years. This means that it is likely that only around a quarter of all children with cerebral palsy will be accepted. Selecting the children most in need of specialist palliative care poses a challenge, in view of the unpredictability and uncertainty in the natural history of the condition. Most children succumb to respiratory illness, severe epilepsy or gastrointestinal problems ${ }^{(5,6,7,8)}$. Considering cerebral palsy alone, of the approximately 2 in 1000 children known to have cerebral palsy at 12 months of age, $15 \%$ die before age $7^{(9)}$.

Medications and/or surgery may help to reduce spasticity, hyperreflexia, and clonus, although they do not improve weakness and incoordination [10,11] Furthermore, whether these interventions improve functional outcomes is uncertain. Feeding problems and oromotor dysfunction(drooling)are common in children with $\mathrm{CP}^{[12,13,14]}$. Infants frequently have sucking and swallowing difficulties $^{[15]}$. In school-aged children, common problems include needing help with feeding, prolonged feeding time ( $>3$ hours/day), choking, and frequent vomiting ${ }^{[15]}$ Parents of a child with $\mathrm{CP}$ may experience chronic grief, as well as guilt, frustration, denial, anger, resentment, and embarrassment $^{(16)}$. They may limit themselves socially and strain relationships with their spouse and other children.

This study conducted in IGMC, Shimla H.P. was the first study conducted in this institution which assessed need of Pediatric palliative care in children with cerebral palsy.

In this study it was found that every child with severe cerebral palsy requires palliative care. Estimated life expectancy of the children enrolled in the study was greater than 2 years, still each required early initiation of palliative care. Though there is no current treatment which can cure the disease fully, current treatment given to these children improved their current performance status with minimal side effects. More the degree of performance decline and greater the number of symptoms in a child, greater was the need for urgent palliative care. Majority of children in the study had spasticity, seizures, pain, feeding problems and urinary incontinence. The higher number of children with such symptoms in the study emphasis its contribution in palliative care needs. Further is was found that majority of parents as well as siblings of children with cerebral palsy suffered from psychological distress. Parents of such children themselves asked for palliative care.

So this study concludes that every child of severe cerebral palsy needs palliative care and it must be initiated as soon as diagnosis is made.

\section{Declaration}

Funding- none

Declaration- none

Ethical issues- permission taken from ethical committee IGMC Shimla H.P.

\section{References}

1. World Health Organization. Cancer pain relief and palliative care in children. Geneva: WorldHealth Organization, 1998.

2. woods2010 ref : ACT/RCPCH a guide to development of child's palliative care services: a report of the joint working party , Bristol 1997)

3. Glare PA, Eychmueller S, McMahon P: Diagnostic accuracy of the palliative prognostic score in hospitalized patients with advanced cancer. J Clin Oncology. 2004, $22 \quad$ (23): $\quad 4823-4828$. 10.1200/JCO.2004.12.056.

4. Maltoni M, Caraceni A, Brunelli C, Broeckaert B, Christakis N, Eychmueller S, Glare P, Nabal M, Vigano A, Larkin P: Prognostic factors in advanced cancer patients: evidence-based clinical recommendations-a study by the Steering Committee of the European Association for Palliative Care. J Clin Oncology. 2005, 
23

(25):

6240-6248.

10.1200/JCO.2005.06.866.

5. Hutton JL \& Pharoah POD (2006) Life expectancy in severe cerebral palsy Arch Dis Child 91: 254- 258

6. Baird G, Allen E et al (2011) Mortality from 1 to $16-18$ in bilateral cerebral palsy Arch Dis Child 96(11): 1077-1081

7. Crichton JU, Mackinnon M \& White CP (1995) The life-expectancy of persons with cerebral palsy. Dev Med \& Child Neurol 37(7): 567-576

8. G, Hutton JL \& Pharoah POD (1999) Cause of death in cerebral palsy: a descriptive study, Arch Dis Child 81(5): 390-394

9. Paneth N, Hong T, Korzeniewski S. The descriptive epidemiology of cerebral palsy. Clin Perinatol 2006;33(2):251-67.

10. Glenn MB, Whyte J. The Practical Manage ment of Spasticity in Children and Adults, Lea \& Fegiber, Philadelphia 1990.

11. Quality Standards Subcommittee of the American Academy of Neurology and the Practice Committee of the Child Neurology Society, Delgado MR, Hirtz D, et al. Practice parameter: pharmacologic treatment of spasticity in children and adolescents with cerebral palsy (an evidence-based review): report of the Quality Standards Subcommittee of the American Academy of Neurology and the Practice Committee of the Child Neurology Society. Neurology 2010; 74:336.

12. Dahl M, Thommessen M, Rasmussen M, Selberg T. Feeding and nutritional characteristics in children with moderate or severe cerebral palsy. Acta Paediatr 1996; 85:697.
13. Reilly S, Skuse D, Poblete X. Prevalence of feeding problems and oral motor dysfunction in children with cerebral palsy: a community survey. J Pediatr 1996; 129:877.

14. Andrew MJ, Parr JR, Sullivan PB. Feeding difficulties in children with cerebral palsy. Arch Dis Child Educ Pract Ed 2012; 97:222.

15. Sullivan PB, Lambert B, Rose M, et al. Prevalence and severity of feeding and nutritional problems in children with neurological impairment: Oxford Feeding Study. Dev Med Child Neurol 2000; 42:674.

16. Olshansky S. Chronic sorrow: A response to having a mentally defective child. Soc Casework 1962; 43:190. 